\title{
A guide to contraindications to childhood vaccinations
}

$\mathrm{T}$ he infant and childhood immunization program in Canada has led to extraordinary decreases in serious infections with diphtheria, tetanus, pertussis, polio, Haemophilus influenzae type $\mathrm{b}$, hepatitis $\mathrm{B}$, measles, mumps and rubella. There is a danger that this successful immunization program may lead to complacency about vaccine preventable illnesses such that parents, and sometimes physicians, may become too focused on potential adverse events of vaccination and lose sight of the serious and sometimes even fatal consequences of the disease being prevented. Physicians and parents need reliable accurate information on true contraindications so that opportunities to immunize an infant or child are not missed. In fact, there are very few true contraindications. Deferral or delay of immunization based on misconceptions about contraindications puts an infant or child at risk. The following tables summarize the answers to the most frequently raised questions about contraindications. Tables 1 to 3 are based upon recommendations from the National Advisory Committee on Immunization (1) and the American Advisory Committee on Immunization (2). Additional information written for parents is available in the publication entitled, Your Child's Best Shot (3).

\section{REFERENCES}

1. National Advisory Committee on Immunization. Canadian Immunization Guide, 5th edn. Ottawa: Health Canada, 1998.

2. Recommended childhood immunization schedule - United States, 1999. MMWR Morb Mortal Wkly Rep 1999;48(01):12-6.

3. Canadian Paediatric Society. Your Child's Best Shot: A Parent's Guide To Vaccination. Ottawa: Canadian Paediatric Society, 1997.

TABLE 1: Contraindications to childhood vaccinations as recommended by the National Advisory Committee on Immunization and the American Advisory Committee on Immunization

\begin{tabular}{|c|c|}
\hline Symptom or condition & Contraindication \\
\hline \multicolumn{2}{|l|}{ Allergy } \\
\hline \multicolumn{2}{|l|}{ Anaphylactic (life-threatening) allergy to: } \\
\hline a) Previous dose of vaccine & That vaccine \\
\hline b) Neomycin & $\begin{array}{l}\text { Inactivated polio vaccine (IPV), DtaP-IPV-Haemophilus influenzae type b (Pentacel, Aventis } \\
\text { Pasteur, Toronto, Ontario), measles-mumps-rubella (MMR) vaccine and varicella vaccine }\end{array}$ \\
\hline c) Gelatin & Varicella vaccine and MMR vaccine \\
\hline f) Streptomycin & IPV \\
\hline \multicolumn{2}{|l|}{ Immunodeficient state } \\
\hline \multicolumn{2}{|l|}{ a) Recipient } \\
\hline $\begin{array}{l}\text { - congenital immunodeficiency, eg, severe } \\
\text { combined immunodeficiency }\end{array}$ & $\begin{array}{l}\text { MMR vaccine, varicella vaccine, oral polio vaccine }(\mathrm{OPV}) * \text { and bacille Calmette-Guérin (BCG) } \\
\text { vaccine }\end{array}$ \\
\hline \multicolumn{2}{|l|}{ b) Household contacts } \\
\hline - congenital immunodeficiency & OPV* \\
\hline - HIV & OPV* \\
\hline c) Systemic steroids, high dose & Defer MMR, varicella vaccine, BCG vaccine and OPV* \\
\hline Pregnancy & MMR and varicella vaccine \\
\hline
\end{tabular}

*OPV use is no longer recommended in Canada due to the risk, albeit low, of paralysis; IPV has no such associated risk. DTaP Diphtheria, tetanus, acellular pertussis 
TABLE 2: Precautions to childhood vaccinations as recommended by National Advisory Committee on Immunization and the American Advisory Committee on Immunization

\begin{tabular}{ll}
\hline Symptom or condition & Precaution or action \\
\hline Moderate or severe illness with or without fever & $\begin{array}{c}\text { Defer only if the child is NOT in immediate danger of exposure to the disease or the child is } \\
\text { likely to return to continue immunization in a timely fashion } \\
\text { Intravenous and intramuscular gammaglobulin can interfere with measles-mumps-rubella } \\
\text { (MMR) vaccine and varicella vaccine }\end{array}$ \\
$\begin{array}{ll}\text { Delay MMR three to } 10 \text { months; time depends upon immunoglobulin amount } \\
\text { Delay varicella vaccine for five months if intravenous immune globulin (IVIG) and varicella } \\
\text { immune globulin (VZIG) given }\end{array}$ \\
Defer MMR and varicella vaccine until immediate postpartum
\end{tabular}

TABLE 3: Noncontraindications to childhood vaccination as recommended by National Advisory Committee on Immunization and the American Advisory Committee on Immunization

\begin{tabular}{|c|c|}
\hline Symptom or condition & Action \\
\hline Mild to moderate local reaction to previous injection of vaccine & Immunize \\
\hline Mild acute illness with or without fever & Immunize \\
\hline Recovering from an acute illness & Immunize \\
\hline Premature infant & Immunize on time - do NOT delay \\
\hline Recent exposure to an infectious disease & Immunize \\
\hline Duck meat, duck feathers & Immunize \\
\hline Molds, grasses, pollens, etc & Immunize \\
\hline Eggs & $\begin{array}{l}\text { Immunize except for influenza vaccine; NO contraindication to } \\
\text { measles-mumps-rubella (MMR) vaccine }\end{array}$ \\
\hline Tuberculosis (TB) or positive TB skin test & Immunize even with MMR and varicella vaccine \\
\hline Family history of seizures & Immunize \\
\hline $\begin{array}{l}\text { Persistent inconsolable crying } 3 \mathrm{~h} \text { or more within } 48 \mathrm{~h} \text { after prior dose of } \\
\text { DTA or DtaP }\end{array}$ & Immunize \\
\hline Pregnancy & $\begin{array}{l}\text { Immunize with tetanus, hepatitis } B \text {, influenza and inactivated polio } \\
\text { vaccines as required }\end{array}$ \\
\hline History of Haemophilus influenzae type b disease & Immunize Haemophilus influenzae type b vaccine \\
\hline $\begin{array}{l}\text { Hypotonic-hyporesponsive state within } 48 \mathrm{~h} \text { after prior dose of DtaP } \\
\text { containing vaccine }\end{array}$ & $\begin{array}{l}\text { Not necessary to defer because episodes may occur with both DT, DTaP; } \\
\text { continued immunization with all antigens is recommended }\end{array}$ \\
\hline
\end{tabular}

aP Acellular pertussis; D Diphtheria; P Pertussis; $T$ Tetanus

This article also appears in Paediatr Child Health 2000;5(1):11-12. 


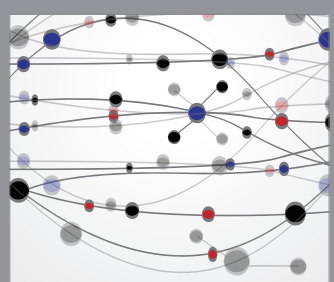

The Scientific World Journal
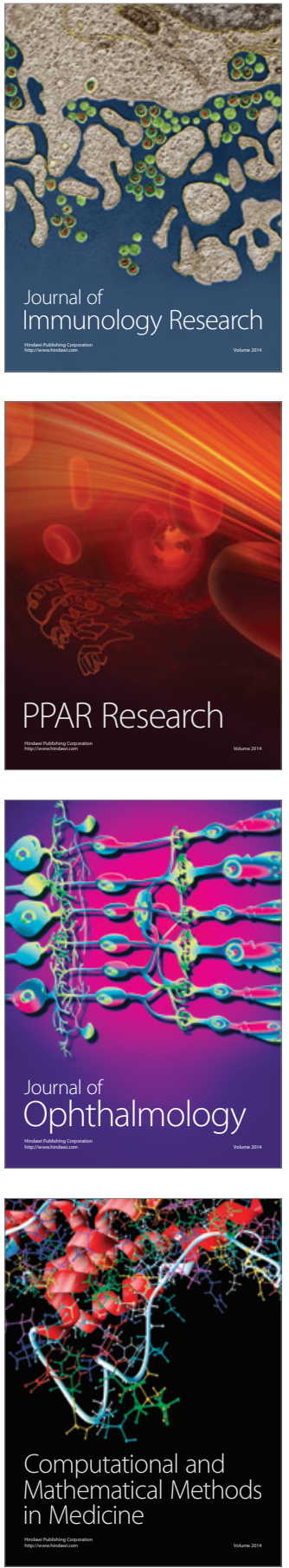

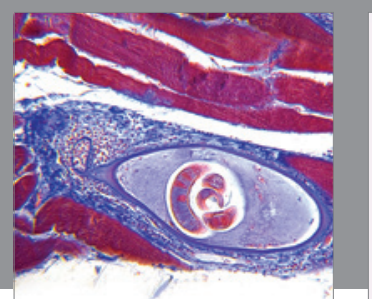

Gastroenterology Research and Practice

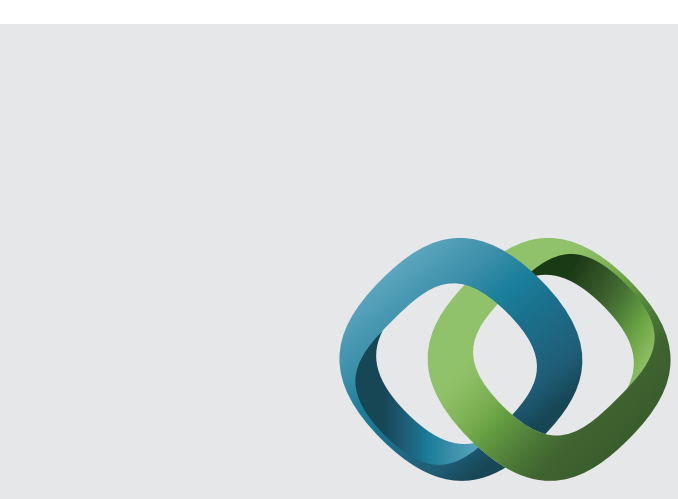

\section{Hindawi}

Submit your manuscripts at

http://www.hindawi.com
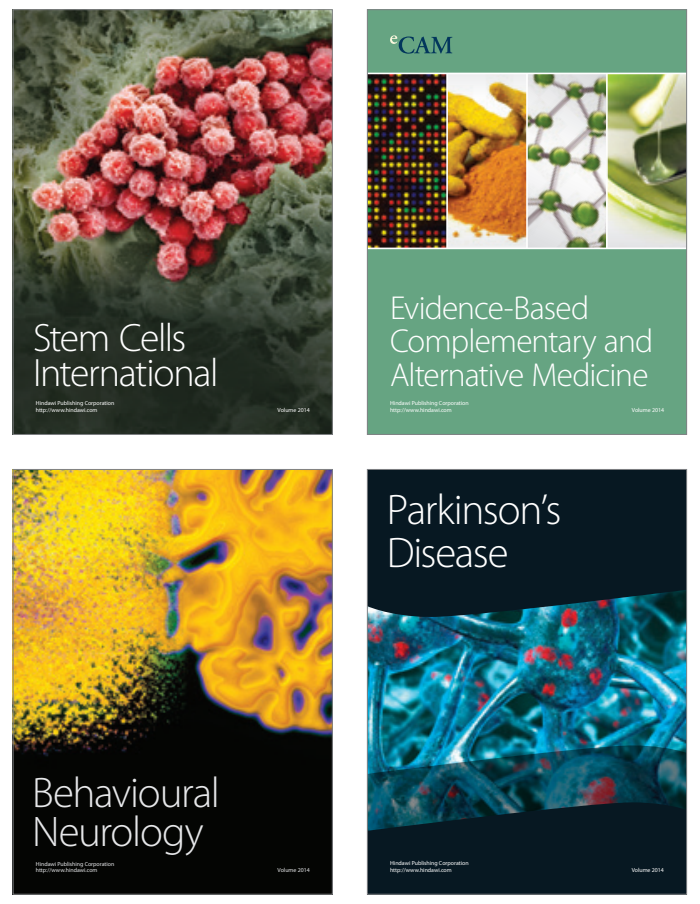
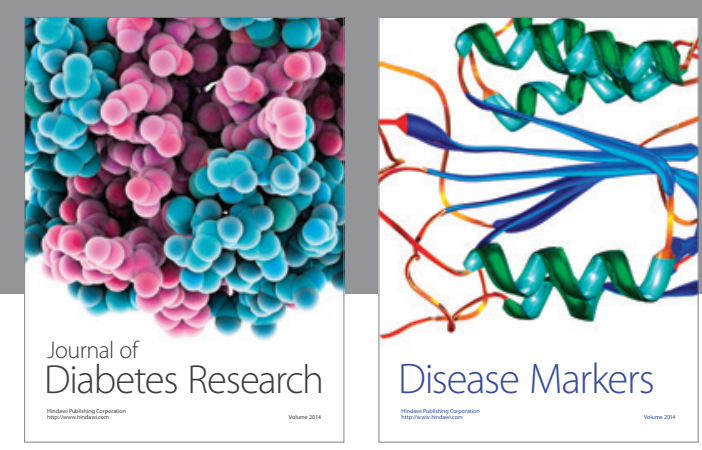

Disease Markers
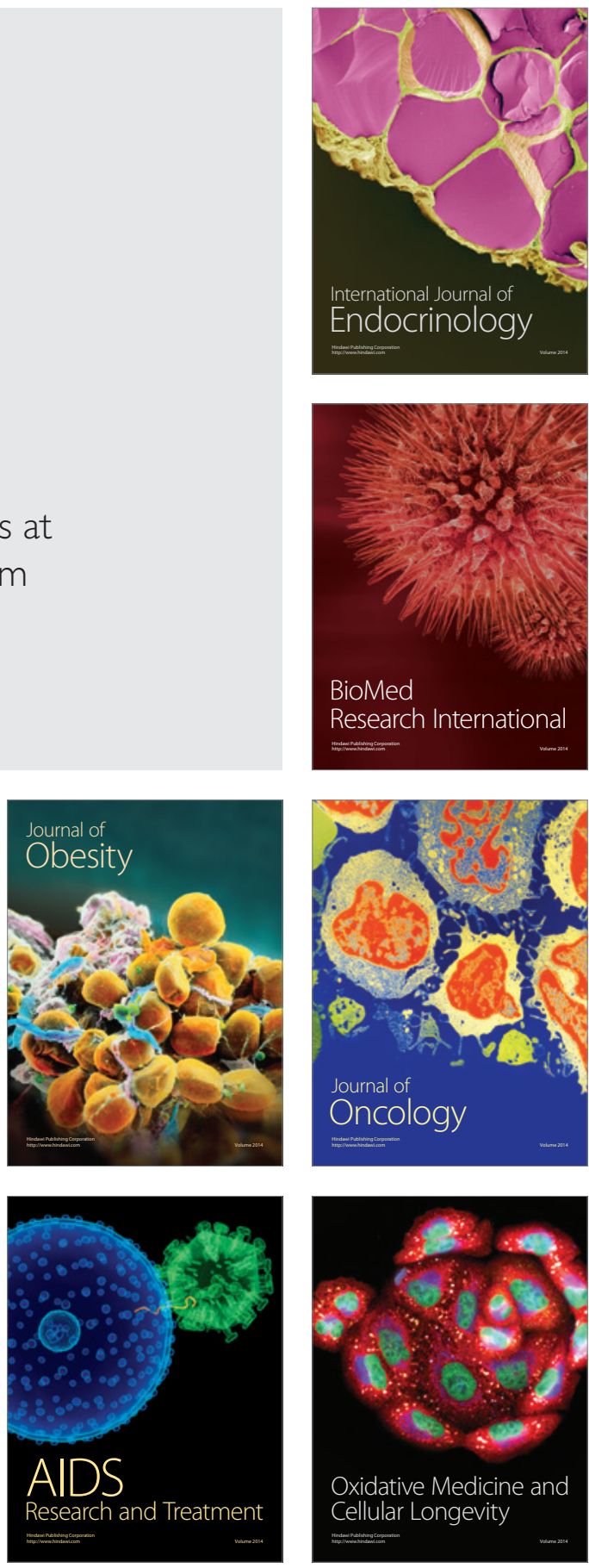